\title{
Quick assessment of influenza a virus infectivity with a long-range reverse- transcription quantitative polymerase chain reaction assay
}

Yuki Nakaya* (D, Takashi Fukuda, Hiroki Ashiba, Masato Yasuura and Makoto Fujimaki

\begin{abstract}
Background: The polymerase chain reaction (PCR) is commonly used to detect viral pathogens because of its high sensitivity and specificity. However, conventional PCR methods cannot determine virus infectivity. Virus infectivity is conventionally examined with methods such as the plaque assay, even though such assays require several days. Long-range reverse-transcription quantitative PCR (RT-qPCR) has previously been suggested for the rapid assessment of RNA virus infectivity where the loss of infectivity is attributable to genomic fragmentation.

Methods: IAV was irradiated with $253.7 \mathrm{~nm}$ ultraviolet (UV) rays to induce genomic strand breaks that were confirmed by a full-length RT-PCR assay. The IAV was then subjected to plaque assay, conventional RT-qPCR and long-range RT-qPCR to examine the relationship between infectious titer and copy number. A simple linear regression analysis was performed to examine the correlation between the results of these assays.

Results: A long-range RT-qPCR assay was developed and validated for influenza A virus (IAV). Although only a few minutes of UV irradiation was required to completely inactivate IAV, genomic RNA remained detectable by the conventional RT-qPCR and the full-length RT-PCR for NS of viral genome following inactivation. A long-range RTqPCR assay was then designed using RT-priming at the $3^{\prime}$ termini of each genomic segment and subsequent qPCR of the $5^{\prime}$ regions. UV-mediated IAV inactivation was successfully analyzed by the long-range RT-qPCR assay especially when targeting PA of the viral genome. This was also supported by the regression analysis that the longrange RT-qPCR is highly correlated with plaque assay (Adjusted $R^{2}=0.931, P=0.000066$ ).
\end{abstract}

Conclusions: This study suggests that IAV infectivity can be predicted without the infectivity assays. The rapid detection of pathogenic IAV has, therefore, been achieved with this sensing technology.

Keywords: Influenza virus, Ultraviolet rays, Long-range RT-qPCR, Infectivity, Strand break, Water treatment

\footnotetext{
* Correspondence: nakaya.yuki@aist.go.jp

Sensing System Research Center, National Institute of Advanced Industrial Science and Technology (AIST), Central 5, 1-1-1 Higashi, Tsukuba, Ibaraki 305-8565, Japan
}

C C The Author(s). 2020 Open Access This article is licensed under a Creative Commons Attribution 4.0 International License, which permits use, sharing, adaptation, distribution and reproduction in any medium or format, as long as you give appropriate credit to the original author(s) and the source, provide a link to the Creative Commons licence, and indicate if changes were made. The images or other third party material in this article are included in the article's Creative Commons licence, unless indicated otherwise in a credit line to the material. If material is not included in the article's Creative Commons licence and your intended use is not permitted by statutory regulation or exceeds the permitted use, you will need to obtain permission directly from the copyright holder. To view a copy of this licence, visit http://creativecommons.org/licenses/by/4.0/ The Creative Commons Public Domain Dedication waiver (http://creativecommons.org/publicdomain/zero/1.0/) applies to the data made available in this article, unless otherwise stated in a credit line to the data. 


\section{Background}

Various techniques for virus detection have been developed [1-12]. Polymerase chain reaction (PCR) is one of the most commonly used methods to detect viruses in specimens because of its rapidity and high sensitivity [4, $7,8]$. With the recent growing demand for the rapid diagnosis of viral infection, novel techniques and devices based on PCR have been developed [13, 14]. These newer methods mostly shorten the assay time and reduce the proportion of false negatives. Despite these advances in PCR technology, PCR still cannot clearly discriminate between infectious and non-infectious organisms [15]. Virus infectivity is conventionally measured with infection studies incorporating methods such as the plaque assay or focus assay using cell cultures or animals $[1,4,16]$. Although these studies take several days to complete, they remain in common use for examining virus infectivity because of their reliability [17]. However, both reliability and rapidity are required for on-site inspections at the places such as hospitals, water treatment plants, and food plants. Alternative strategies for infectivity evaluation have previously been suggested in studies of both DNA (adenovirus, parvovirus, hepatitis $\mathrm{B}$ virus) and RNA (norovirus, MS2 bacteriophage) viruses [18-22]. Notably, long-range quantitative PCR (qPCR) was commonly employed in each of these studies. Long-range qPCR methods basically aim to exclude degraded genomes from the samples being tested as these nucleic acids are derived from viral particles that are no longer infective. In the case of DNA viruses, genomic DNA is pre-amplified by long-range PCR to prepare the 4-6 kbp PCR template required for the subsequent nested qPCR $[19,21]$. Failure of viral DNA detection or decreased signal with the nested qPCR reflects the degree of genomic damage. As for RNA viruses, long-range reverse-transcription (RT) is first carried out to prepare complementary DNA (cDNA) prior to qPCR $[18,20]$. Subsequent qPCR needs to take place at a locus that is separate from the RT-priming site to reduce the influence of fragmented RNA. This method was named long-range RT-qPCR. These genomic damages represent the inability of viral replication. Ultraviolet (UV) rays are the powerful sterilizing sources that introduce genomic damages in pathogens [23]. A maximum sterilizing effect of UV rays on pathogens are shown at $253.7 \mathrm{~nm}[23,24]$.

Influenza A virus (IAV) is classified as part of the Orthomyxoviridae family and its genome comprises eight segments of single-stranded, negative-sense RNA [25]. IAV is one of the pathogens of most concern in healthcare as it causes a cold-like illness with symptoms that can be particularly severe in the elderly and infants [26]. IAV occasionally recombines its genes among the different subtypes, resulting in the generation of new subtypes
[27]. These emerging subtypes can potentially cause pandemics because no population has ever experienced some of the antigens on these viruses [27]. In the pandemic situations, quick assessment of IAV infectivity, such as long-range RT-qPCR, is quite important to build a strategy for preventing spread of infection. The longest IAV genomic segments are approximately $2.3 \mathrm{~kb}$ in length and comprise segments 1 (PB2), 2 (PB1), and 3 (PA), which encode subunits of an RNA-dependent RNA polymerase [25]. The RNA polymerase plays an essential role in virus genome replication, which requires the interaction of each subunit. Therefore, strand breaks in these genomic segments should be correlated with IAV inactivation. A long-range RT-qPCR with a PCR site $2.3 \mathrm{~kb}$ upstream of the RT-priming site was used to predict human norovirus GI and GII infectivity in a previous study [20]. The results indicated that long-range RT-qPCR would potentially be applicable to the assessment of IAV infectivity by targeting PB2, PB1 and PA.

In this study, we focused on the development of a rapid testing method for examining IAV infectivity without the use of cell culture or animals. Here, therefore, we investigated whether long-range RT-qPCR is applicable to determination of IAV infectivity. We also appraised the proper length of the target for long-range RT-qPCR by comparing the results for each segment.

\section{Methods}

\section{Cell culture and virus preparation}

Madin-Darby Canine Kidney (MDCK) cells (accession no. CCL-34, ATCC, Manassas, VA) were maintained at $37^{\circ} \mathrm{C}$ and $5 \% \mathrm{CO}_{2}$ in the culture media [Dulbecco's Modified Eagle's Medium (Fujifilm Wako Pure Chemical Corporation, Osaka, Japan) supplemented with $10 \%$ fetal bovine serum (Fujifilm Wako Pure Chemical Corporation), $100 \mathrm{U} / \mathrm{mL}$ penicillin, and $100 \mu \mathrm{g} / \mathrm{mL}$ streptomycin (Fujifilm Wako Pure Chemical Corporation)]. IAV (Panama/2007/99/H3N2) was propagated in the MDCK cells. Culture supernatant aliquots were stored as IAV stocks at $-80^{\circ} \mathrm{C}$ prior to use. The titer of the IAV stocks was determined by plaque assay as described below.

\section{UV irradiation of IAV}

The IAV stocks were irradiated with a UV lamp with a wavelength and fluence of $253.7 \mathrm{~nm}$ and $12.5 \mu \mathrm{W} / \mathrm{cm}^{2}$, respectively, to introduce strand breaks in the virus genome. UV-irradiated IAV was subjected to plaque assay and RNA isolation. The effect of UV irradiation on IAV infectivity was examined by plaque assay as described above. Isolated RNA was used for RT-PCR analyses.

\section{Plaque assay}

IAV infectious titer was analyzed by plaque assay according to a previous report [4] with slight 
modifications. Briefly, MDCK cells were split into 6-well culture plates at the concentration of $5 \times 10^{5}$ cells/well. An aliquot of IAV stocks was thawed and 10-fold serially diluted in the culture media. MDCK cells were inoculated with $400 \mu \mathrm{L}$ of each IAV dilution and incubated at $37^{\circ} \mathrm{C}$ for $1 \mathrm{~h}$ with rocking every $15 \mathrm{~min}$. The inoculum was removed and the cells were washed once with phosphate-buffered saline (-) to eliminate the unbound virus particles. The cells were overlaid with overlay media [KM220 (Kohjin-bio, Saitama, Japan) containing $1.25 \mu \mathrm{g} / \mathrm{mL}$ acetylated trypsin (Sigma-Aldrich Japan, Tokyo, Japan) and $0.8 \%(\mathrm{w} / \mathrm{v})$ SeaPlaque agarose (Lonza Japan K.K., Tokyo, Japan)] and additionally incubated at $37^{\circ} \mathrm{C}$ for $72 \mathrm{~h}$. Cells were fixed and stained in $20 \%$ ethanol containing $1 \%$ crystal violet at room temperature for $15 \mathrm{~min}$ to visualize the plaques. The plaque number was counted and multiplied by the dilution ratio to calculate the infectious titer. Infectious titers were defined as the number of plaque-forming units $(\mathrm{pfu}) / \mathrm{mL}$ and data represent the mean \pm standard error of four independent experiments.

\section{Conventional RT-qPCR}

A conventional RT-qPCR assay was conducted to measure the IAV copy number. Viral RNA was isolated from $140 \mu \mathrm{l}$ virus suspension using the QIAamp Viral RNA Mini Kit (Qiagen K.K., Tokyo, Japan) according to the manufacturer's instructions. Each RNA was eluted in $60 \mu \mathrm{l}$ of an elution buffer. The isolated RNA was immediately subjected to RT-qPCR with the TaqMan Fast Virus 1-Step Master Mix (Thermo Fisher Scientific K.K., Tokyo, Japan), a TaqMan probe (5'-FAM-ATYTCGGC TTTGAGGGGGCCTG-MGB-3'), and a primer pair (Forward: 5'-CCMAGGTCGAAACGTAYGTTCTCTCT ATC-3', Reverse: 5'-TGACAGRATYGGTCTTGT CTTTAGCCAYTCCA-3'). The probe and primer sequences were derived from the IAV diagnosis manual released by the World Health Organization (WHO) [28]. Thermal cycling was carried out on the LightCycler 96 (Roche Diagnostics K.K., Tokyo, Japan) for reverse transcription at $50^{\circ} \mathrm{C}$ for $5 \mathrm{~min}$, denaturation of the RT polymerase at $95^{\circ} \mathrm{C}$ for $20 \mathrm{~s}$, and 40 cycles of PCR at $95^{\circ} \mathrm{C}$ for $3 \mathrm{~s}$ and $60^{\circ} \mathrm{C}$ for $30 \mathrm{~s}$. Copy number quantification was carried out with an IAV standard curve. In brief, for the standard sample preparation, each PCR fragment was purified from agarose gel electrophoresis using QIAquick Gel Extraction kit (Qiagen K.K.), measured the concentration by a spectrophotometer Nanodrop (Thermo Fisher Scientific K.K.), then determined the copy number using DNA Copy Number and Dilution Calculator (Thermo Fisher Scientific K.K.). These standard samples were 10-fold serially diluted and subjected to the real-time RT-qPCR analyses at the same time with the IAV samples to make standard curves. Copy numbers of each time point was divided by that of $0 \mathrm{~min}$ (No UV) to calculate the copy number ratio. Assay was performed in a triplicate experiment.

\section{Long-range RT-qPCR}

$\mathrm{PB} 2, \mathrm{~PB} 1$, and PA were analyzed by long-range RTqPCR to evaluate the effect of UV irradiation. RNA was identically isolated from virus suspension and reversetranscribed using SuperScript III (Thermo Fisher Scientific K.K.) with an RT primer (5'-AGCGAAAGCAGG$\left.3^{\prime}\right)$ that specifically primed at the $3^{\prime}$ termini of $\mathrm{PB} 2$, PB1, and PA of IAV (Panama/2007/99/H3N2) [29]. qPCR was performed using Power SYBR Green PCR Master Mix (Thermo Fisher Scientific K.K.) according to the manufacturer's instructions. Thermal cycling was carried out on the LightCycler 96 for activation of the DNA polymerase at $95^{\circ} \mathrm{C}$ for $10 \mathrm{~min}$, and 40 cycles of PCR at $95^{\circ} \mathrm{C}$ for $15 \mathrm{~s}$ and $60^{\circ} \mathrm{C}$ for $1 \mathrm{~min}$. qPCR primers for each segment were designed with Primer3Plus (http://www.bioinformatics.nl/cgi-bin/primer3plus/primer3plus.cgi) to amplify the region more than $2 \mathrm{~kb}$ away from the RT-priming sites. Segments 4 to 8 (HA, NP, NA, $M$, and NS) were similarly examined by long-range RT-qPCR, with an RT primer (5'-AGCAAAAGCAGG$\left.3^{\prime}\right)$ and the qPCR primers for each segment designed by Primer3Plus to amplify the region within $250 \mathrm{bp}$ of the $5^{\prime}$ termini. All of the $\mathrm{qPCR}$ primer sequences are available upon request. A denaturing protocol was carried out in the RT-qPCR to check the denaturing temperature of PCR products, that is commonly employed to verify the primer specificity. Quantification of the copy numbers was performed with standard curves as shown in the subsection of conventional RTqPCR. Values below that of the most diluted standard were defined as "not detected" and included in the datasets as 0 . The cut-off copy numbers were considered as below $2.35,44.2,1.95,1.77,4.45,1.08$, and 7.80 copies/ $\mu \mathrm{l}$ for PB2, PA, HA, NP, NA, M, and NS, respectively. Copy number ratio was calculated as shown in the subsection of conventional RT-qPCR. Assays were conducted in triplicate experiments and repeated for three times.

\section{Full-length RT-PCR}

The degrees of RNA degradation of PA and NS were examined by full-length RT-PCR. Same cDNAs prepared in the long-range RT-qPCR were subjected to RT-PCR using PrimeStar Max DNA polymerase (TaKaRa, Shiga, Japan) according to the manufacturer's instruction. Thermal cycling was carried out on the MiniAmpPlus Thermal Cycler (Thermo Fisher Scientific K.K.) for activation of the DNA polymerase at $98^{\circ} \mathrm{C}$ for $1 \mathrm{~min}, 40 \mathrm{cy}$ cles of PCR at $98^{\circ} \mathrm{C}$ for $10 \mathrm{~s}, 55^{\circ} \mathrm{C}$ for $5 \mathrm{~s}$ and $72^{\circ} \mathrm{C}$ for $2 \mathrm{~min}$, and for deactivation of the DNA polymerase at $72{ }^{\circ} \mathrm{C}$ for $7 \mathrm{~min}$. Primer sets were designed to amplify 
most of the segments of PA (2105 bp of $2338 \mathrm{bp}$, Forward: 5'-GCTTCAACCCGATGATTGTC-3', Reverse: 5'-GGAGTTGAACCAAGACGCAT-3') and NS (558 bp of $887 \mathrm{bp}$, Forward: 5'-GAACTGAGTGATGCCCCA TT-3', Reverse: 5'-TCCCCCATTCTCATTACTGC-3') which include the regions of the long-range RT-qPCR.

\section{Statistics}

The significances of all the datasets in plaque assay, the conventional RT-qPCR, and the long-range RT-qPCRs were verified by the Kruskal-Wallis test. Student's t-test was conducted to assess the significance between specific two different datasets of averaged technical replicates in the long-range RT-qPCRs and plaque assay. A simple linear regression analysis was conducted using IBM SPSS Statistics (IBM Japan Ltd., Tokyo, Japan) to examine the significant correlation between the plaque assay and each long-range RT-qPCR as well as the conventional RT-qPCR. All the significances were considered to have $P<0.05$.

\section{Results}

\section{Effect of UV irradiation on IAV infectivity}

IAV stocks were irradiated with a UV lamp for increasing periods of time from $15 \mathrm{~s}$ to $5 \mathrm{~min}$ and the plaque assay was then conducted to determine the required length of time for UV irradiation to completely inactivate the IAV stocks (Fig. 1a and b). The infectivity decreased with increasing length of UV exposure. The original titer of $2.2 \times 10^{7} \mathrm{pfu} / \mathrm{mL}$ (No UV) dropped to
$1.9 \times 10 \mathrm{pfu} / \mathrm{mL}$ by $3 \mathrm{~min}$ of irradiation $(P<0.05)$. IAV replication completely ceased after $4 \mathrm{~min}$ or more of UV irradiation $(P<0.05,4 \mathrm{~min}$ vs. No UV). Even after $3 \mathrm{~min}$ of irradiation, plaques were not observed in two of the four replicate experiments. The not observed values were considered as $0 \mathrm{pfu} / \mathrm{ml}$ and included in the calculation for titers. These results indicated that $4 \mathrm{~min}$ of UV irradiation was sufficient to inactivate the IAV stocks.

\section{Influence of UV irradiation on strand breaks in the IAV genome}

IAV copy number in the UV-irradiated virus suspensions was quantified by RT-qPCR to evaluate the degree of genomic RNA degradation (Fig. 2). Here, we used the primer and probe set suggested by the WHO for IAV detection, which targets $\mathrm{M}$ of IAV genomic segment. The PCR product size and primer specificity were verified in the agarose-gel electrophoresis (Fig. 2a). IAV copy number and the infectious titer decreased with longer UV exposure (Fig. 2b). Approximately $90 \%$ of the genome was reduced after 4-5 min of UV exposure $(P<$ $0.001)$, at which point IAV lost infectivity. This result suggested that the loss of infectivity caused by UV irradiation was associated with genomic strand breaks as reported previously [30]. However, genomic RNA was still detectable by RT-qPCR. Even after overnight UV irradiation, the IAV genome was faint but still detected with a small copy number (data not shown). While the conventional RT-qPCR employed here is useful to detect and quantify IAV in specimens as outlined in the WHO

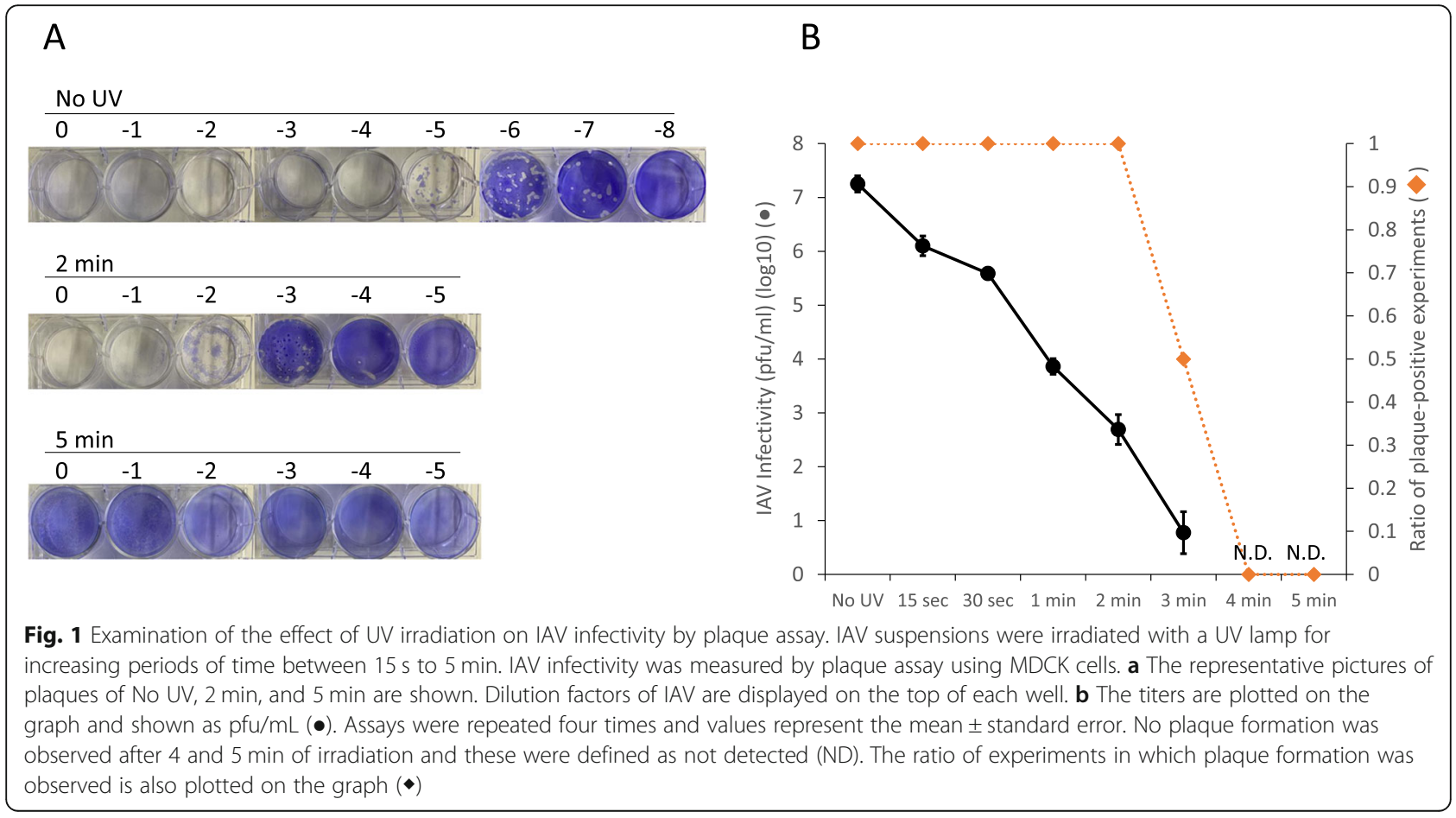




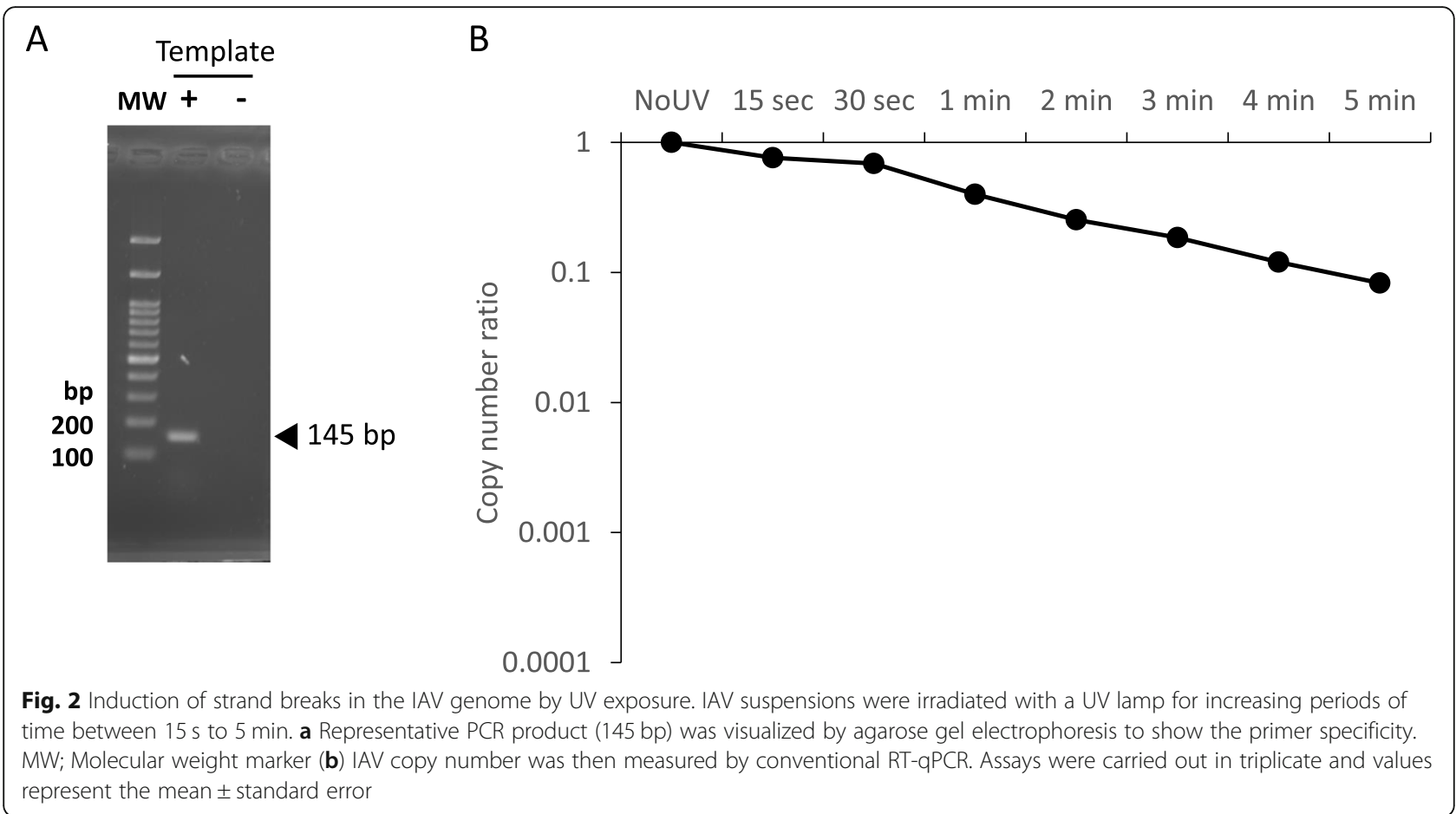

guidelines, other approaches such as long-range RTqPCR need to be developed to assess IAV infectivity.

\section{Eligibility of long-range RT-qPCR to assess IAV infectivity}

The lengths of IAV (Panama/2007/99/H3N2) PB2 (DQ487334), PB1 (DQ487333), PA (DQ487335), HA (DQ487340), NP (DQ487339), NA (DQ487337), M (DQ487338), and NS (DQ487336) are 2341, 2341, 2233, $1762,1566,1466,1027$, and $887 \mathrm{bp}$, respectively, according to the NCBI GenBank (Fig. 3a). We hypothesized that long-range RT-qPCR would be applicable to at least PB2, PB1, and PA because the distances between the RT-priming sites and the qPCR sites were equivalent to that for human norovirus, which was previously successfully subjected to long-range RT-qPCR. The RT reactions were primed at the $3^{\prime}$ termini using a common RT primer (5'-AGCGAAAGCAGG-3'), followed by qPCR with specific primer pairs for each segment (Fig. 3a). The PCR product size and primer specificity were confirmed by the agarose-gel electrophoresis (Fig. 3b). qPCR was successful for PB2 and PA but not for PB1 with any of the primer pairs we designed (Fig. 3c). We, therefore, did not include PB1 in any further analyses. The copy number was reduced with increasing length of UV irradiation and approximately $99.9 \%$ of the copies were fragmented by $4 \mathrm{~min}$ for both PB2 and PA $(P<0.001)$ (Fig. 3c). In particular, PA was detectable only in three, one, and zero replicates out of nine at the time points of 3 , 4, and $5 \mathrm{~min}$, respectively, while PB2 was still detectable in every replicate at each time point. Next, we also performed long-range RT-qPCR for the other segments to evaluate their importance in the assay. A common RT primer (5'-AGCAAAAGCAGG-3') and specific primer pairs were used for each segment (Fig. 3a). The PCR products were visualized by electrophoresis as well as PB2 and PA (Fig. 3b). Approximately $99.9 \%$ or more of $\mathrm{HA}, \mathrm{NP}$, and NA were degraded by $4 \mathrm{~min}$ similar to PB2 and PA $(P<0.001)$ (Fig. 3c). In contrast, the reduction ratio of $\mathrm{M}$ and NS was below $99 \%$ at $4 \mathrm{~min}(P<0.001)$. A simple linear regression analysis was conducted to examine the correlation between the results of plaque assay and each long-range RT-qPCR as well as the conventional RT-qPCR (Table 1). All the results obtained in the RT-qPCRs were significantly correlated with the plaque assay $(P<0.05)$. In particular, the long-range $R T$ qPCR for PB2 and PA showed the highest significant values (PB2: adjusted $R^{2}=0.938, P=0.000049$, PA: adjusted $\left.R^{2}=0.931, P=0.000066\right)$ among them. This indicates that the long-range RT-qPCR for PB2 and PA are mostly correlated with the plaque assay and the importance of the lengths of genome.

For further confirmation that the RNA degradation by $\mathrm{UV}$ is size dependent, we tried to visualize the initial RNA directly; however, the RNA amount was too small to visualize in agarose-gel electrophoresis. Therefore, we conducted full-length RT-PCR for PA and NS to compare the efficiency of RNA degradation by UV (Fig. 4). This assay shows the existence and amount of fulllength cDNA which reflect the degradation degree of initial viral RNA. Same cDNA sets used in the long- 


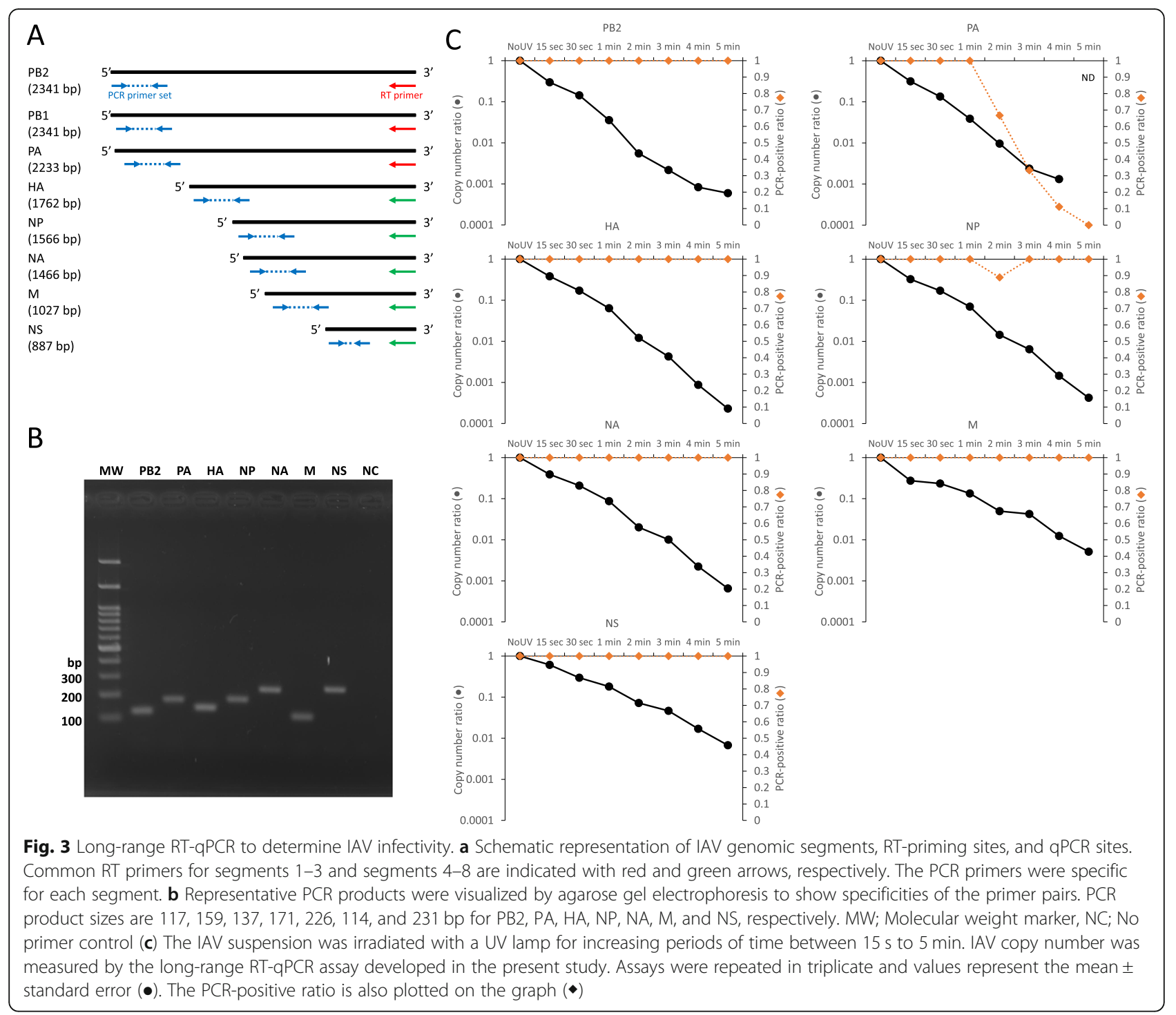

Table 1 Simple linear regression analysis to examine the correlation between plaque assay and the RT-qPCRs

\begin{tabular}{llll}
\hline & Adjusted R2 & F & $P$-value \\
\hline PB2 & 0.938 & 106 & 0.000049 \\
PA & 0.931 & 95.5 & 0.000066 \\
HA & 0.888 & 56.7 & 0.000283 \\
NA & 0.92 & 81.4 & 0.000103 \\
NP & 0.875 & 49.9 & 0.000403 \\
M & 0.928 & 90.5 & 0.000077 \\
NS & 0.861 & 17.2 & 0.006 \\
Conventional RT-qPCR & 0.699 & 6.2 & 0.047
\end{tabular}

Plaque assay and RT-qPCRs were considered as dependent and independent variables, respectively. PB2, $\mathrm{PA}, \mathrm{HA}, \mathrm{NA}, \mathrm{NP}, \mathrm{M}$, and NS indicates the longrange RT-qPCR for PB2, PA, HA, NA, NP, M, and NS, respectively. Adjusted R2: Adjusted correlation coefficient range RT-qPCR were subjected to the full-length RTPCR using PCR primer pairs to amplify $2105 \mathrm{bp}$ and $558 \mathrm{bp}$ for PA and NS, respectively (Fig. 4a and b). Both of PCR products were successfully amplified in No UV sample and reduced as increase of UV exposure time. PA was clearly amplified until $3 \mathrm{~min}$, faintly appeared at $4 \mathrm{~min}$, and completely disappeared at $5 \mathrm{~min}$, while NS was robustly detected in all the samples. These results coincide with the long-range RT-qPCR and indicate that the RNA degradation efficiency is size dependent.

Finally, we compared the sensitivities of the longrange RT-qPCR and the conventional RT-qPCR with the plaque assay (Table 2). The comparison was carried out as follows: the original (No UV) copy number measured in the long-range RT-qPCR of each segment and the conventional RT-qPCR was divided by the original titer of the plaque assay, then the percentages are shown as the normalized sensitivity of the long-range RT-qPCR 


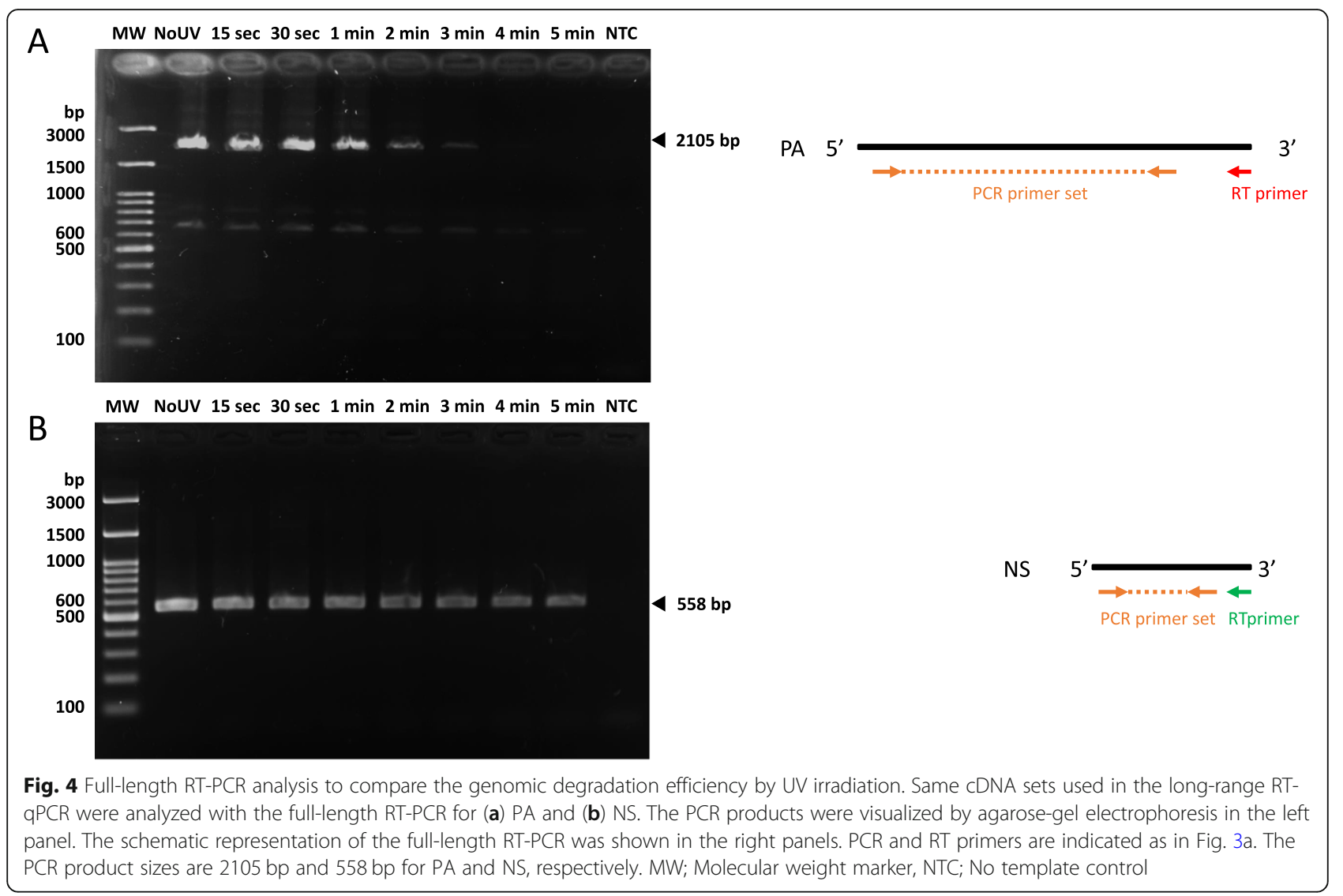

and the conventional RT-qPCR. Normalized sensitivities against the plaque assay range from $24 \%$ (PA) to 43 , 636\% (the conventional RT-qPCR). Interestingly, only the sensitivity of the long-range RT-qPCR for PA was lower than the plaque assay, while the other RT-qPCRs were more sensitive than that. This indicates that these RT-qPCRs except for the long-range RT-qPCR for PA potentially detects extra non-infectious IAVs that are

Table 2 Comparison of sensitivities of the long-range RT-qPCR with the conventional RT-qPCR and the plaque assay

\begin{tabular}{lll}
\hline & $\begin{array}{l}\text { RT-qPCR } \\
\text { (copies/ml) }\end{array}$ & $\begin{array}{l}\text { Normalized to } \\
\text { plaque assay (\%) }\end{array}$ \\
\hline PB2 & $5.7 \times 107$ & 261 \\
PA & $5.4 \times 106$ & 24 \\
HA & $5.3 \times 108$ & 2395 \\
NA & $6.8 \times 108$ & 3109 \\
NP & $4.5 \times 108$ & 2041 \\
M & $3.6 \times 108$ & 1627 \\
NS & $1.5 \times 108$ & 700 \\
Conventional RT-qPCR & $9.6 \times 109$ & 43,636 \\
\hline
\end{tabular}

Original copy numbers measured in the RT-qPCRs were divided by that in the conventional RT-qPCR or the titer in the plaque assay. Values are shown as percentages. PB2, $P A, H A, N A, N P, M$, and NS indicates the long-range RT-qPCR for PB2, PA, HA, NA, NP, M, and NS, respectively. Normalization was performed as follows: RT-qPCR (copies/ml) / Plaque assay $(2.2 \times 107 \mathrm{pfu} / \mathrm{ml})$ not detectable in the plaque assay. In other words, only the long-range RT-qPCR for PA is highly specific for infectious IAVs.

\section{Discussion}

The rapid detection of pathogens is in high demand for the purpose of on-site inspection of specimens at hospitals and of treated water at water treatment plants [31, 32]. In healthcare settings, patients with flu symptoms are usually diagnosed with an IAV diagnostic test using immunochromatography with antibodies against IAV antigens [31]. This rapid antigen test is inexpensive and can be completed within 20-30 min. However, its sensitivity is much lower than that of other tests [3]. We previously showed that an immunochromatographic test commonly used at hospitals in Japan was $10^{5}$-fold less sensitive than qPCR [3]. This indicates that the immunochromatographic test would frequently show false negatives because the IAV copy number can be less than the detection limit of the assay [6]. Indeed, a clinical study showed that most patients are misdiagnosed as negative for influenza virus based on initial testing using immunochromatography [33]. Alternative methods such as RT-qPCR on Roche's cobas Liat System have been developed to address this issue [14]. These newer rapid diagnostic tests target IAV genomic RNA instead of viral 
antigens. This provides not only quicker results turnaround but also sufficient accuracy and sensitivity for hospital-based diagnosis. In addition, this type of test can determine the IAV subtypes responsible by sensing subtype-specific sequences [34]. These are major advantages for public health in terms of preventing epidemics. Recent improvements in UV light-emitting diodes (LED) technology will likely accelerate the installation of UV sanitization where UV irradiation has not been used for this purpose [35]. LEDs are expected to reduce the running costs of UV-based sanitization because of their lower electricity consumption and longer lifespan [35]. A previous study emphasized the importance of UV LED in disinfection for pathogens not only at water treatment plants but throughout the entire water distribution system [36]. This is because a number of contamination cases are considered to have occurred as a result of deficiencies in the distribution system. Some of the highly pathogenic avian influenza viruses, such as the H5N1 and H9N2 subtypes included in IAV, are also considered to be partially transmitted to humans through the consumption of contaminated water [37, 38]. In response to this trend, methods that can be used to verify successful disinfection in real time are desirable [32]. The rapid molecular test based on long-range RTqPCR described in the present study may represent such a solution for this issue.

Again, this study focused on the development of a rapid testing method for examining IAV infectivity without the use of cell culture or animals. We utilized UV irradiation to inactivate IAV by introducing strand breaks into the genomic RNA segments. Viral replication was completely abolished after a few minutes of UV irradiation with degradation of the viral RNA as expected (Fig. 1). However, viral RNA was still detectable even though no infectious IAV was contained in the virus suspensions (Fig. 2). This result agrees with that of a previous study where short wavelength $(280 \mathrm{~nm})$ UVCLED was effective for IAV inactivation based on a plaque assay but where viral genomic RNA continued to yield a positive result by RT-qPCR [30]. In this case, the qPCR site was designed $150 \mathrm{bp}$ upstream of the RT-priming site. In our study, we did not use any specific RTprimers for the conventional RT-qPCR because the commercial RT-qPCR kit we used contained random primers. Random primers are generally considered to bind to most templates. For this reason, a number of cDNAs containing the PCR target sequence were likely also synthesized from adjacent sites. The distance between the qPCR site and the RT-priming site is an important factor in the detection of RNA virus infectivity $[18,20]$. If this distance is too long, more individual viruses will fail to be transcribed into cDNA with no amplification as a result. Here, we showed that long-range
RT-qPCR for each genomic segment produced a similar trend in the infectivity results. PB2, PA, HA, NP, and NA with lengths ranging from 1.5 to $2.3 \mathrm{~kb}$ showed between 99 and $99.9 \%$ degradation after $4-5$ min of irradiation, at which point the virus particles became noninfective. In contrast, $\mathrm{M}$ and NS, which are $1 \mathrm{~kb}$ or less in length, reached less than 99\% reduction after 4-5 min. Based on these observations, it may be good practice to design the qPCR sites more than $1.5 \mathrm{~kb}$ away from the RT-priming site to more clearly observe genomic fragmentation. In particular, PA provides the most accurate indication of the degree of infectivity following UV irradiation (Fig. 3 and Table 1). Fluctuation in the PCR results $(66.7 \%$ negative) at the time point of $3 \mathrm{~min}$ (Fig. 3c for PA) was similar to that observed for the infectivity study in which $50 \%$ of the virus suspensions lost infectivity (Fig. 1b). The positive result obtained for one of the nine replicates at 4 min was not statistically significant when compared with the data at $5 \mathrm{~min}$ (student's t-test, $P=0.346$ ). This indicates that non-infective virus particles that have genomic fragmentation in segments other than PA would occasionally be detected in the assay with a low frequency. This is also supported by the regression analysis and sensitivity analysis in this study (Tables 1 and 2). Unexpectedly, PB2, which is almost the same length as PA, still exhibited a high proportion of positive results at 4 and $5 \mathrm{~min}$ among the replicates. The other segments showed similar results. This might have been the result of differences in RT efficiency between segments rather than an effect of the different segment lengths, although we have not yet fully elucidated this.

The discrepancy between virus copy number and infectivity titer has been often observed in many studies $[3,39]$. This is apparently attributed to the presence of defective virions and virus aggregation [39, 40]. Defective virions are unable to infect for variable reasons including genomic deletions and mutations, lacking receptorbinding ability, and disruption of particles, however, these virions can be positive in PCR-based analysis as long as they retain the target region of PCR [39]. Viruses prepared in cell culture tend to aggregate each other to form big clumps of multiple virions that seem to correspond to single plaque [41]. This reduces the apparent infectivity of the virus preparation even with the presence of extra infectious virions. These are the reason why IAV genome was detected both in the long-range RTqPCR and the conventional RT-qPCR even after the virus lost infectivity by UV exposure. In other words, we might have detected the genomes of defective virions or extra infectious virions of the clumps that were not involved in forming plaques. Indeed, it took us for $24 \mathrm{~h}$ of UV exposure to diminish most of the detectable genomes in the conventional RT-qPCR (data not shown). 
This might be occurred because the conventional RTqPCR was too sensitive. Our long-range RT-qPCR for every segment was much less sensitive than the conventional RTqPCR (Table 2). Particularly, sensitivity of the assay for PA was even lower than plaque assay, which might have reduced the chance to detect non-infectious viruses and increased its specificity for infectious viruses. The detailed studies for this aspect will provide important insight into the successful long-range RT-qPCR establishment.

Although we demonstrated that the long-range RTqPCR targeting PA can be a useful tool to examine the infectivity without cell culture, some of issues remain to be solved. One of the biggest concerns is how the assay is applicable for the other IAV subtypes. This is determined by how the primer binding sites are conserved among the subtypes. The RT-primer suits most of the cases because its binding site is highly conserved across the IAV subtypes [29]. As for the qPCR primers, our in silico analysis suggested that the primer set for PA of the long-range RT-qPCR potentially binds to the other subtypes (H1N1, H2N2, H5N1, H7N9, H9N2) because of the homology of the primer binding sequences (1-5 and $0-1$ mismatches out of 20 -mer in Forward or Reverse primers, respectively) (data not shown). However, further experiments are required to determine the appropriate primer set for all the IAV subtypes.

\section{Conclusions}

In summary, our study indicated that IAV infectivity can be predicted by long-range RT-qPCR targeting PA, in particular, to determine the effect of UV irradiation. Long-range RT-qPCR of the other segments can also provide helpful information to support the results from PA. Although additional studies are required, our findings may assist in the future development of IAV prevention strategies.

\section{Abbreviations}

PCR: Polymerase chain reaction; RT-qPCR: Reverse-transcription quantitative polymerase chain reaction; IAV: Influenza A virus; UV: Ultraviolet; MDCK: Madin-Darby Canine Kidney

\section{Acknowledgments}

We are grateful to Drs. Yoko Aida, Hirotaka Sato, and Shintaro Iwasaki (RIKEN, Saitama, Japan) for their helpful suggestions. We thank Natasha BeetonKempen, Ph.D., from Edanz Group (www.edanzediting.com/ac) for editing a draft of this manuscript.

\section{Authors' contributions}

YN designed the study, performed all the experiments, and wrote the original draft. TF, HA, MY, and MF reviewed and edited the manuscript. All authors read and approved the final manuscript.

\section{Funding}

This study was partly supported by a RIKEN-AIST joint grant, as well as by JSPS KAKENHI (grant numbers $17 \mathrm{H} 01048$ and 19 K15989). These funding sponsors were not involved in the study design; in the collection, analysis, and interpretation of the data; in the writing of the report; or in the decision to submit the article for publication.
Availability of data and materials

All the dataset generated or analyzed during the current study are available from the corresponding author upon request.

Ethics approval and consent to participate

Not applicable.

\section{Consent for publication}

Not applicable.

\section{Competing interests}

The authors declare that they have no competing interests.

Received: 19 February 2020 Accepted: 30 July 2020

Published online: 06 August 2020

\section{References}

1. Nakaya Y, Shojima T, Hoshino S, Miyazawa T. Focus assay on felixdependent feline leukemia virus. J Vet Med Sci. 2010;72:117-21.

2. Nemoto M, Imagawa $H$, Tsujimura K, Yamanaka T, Kondo T, Matsumura T. Detection of equine rotavirus by reverse transcription loop-mediated isothermal amplification (RT-LAMP). J Vet Med Sci. 2010;72:823-6.

3. Takahara Y, Nakaya Y, Yasuura M, Ashiba H, Kumar PKR, Fujimaki M. Comparison of influenza virus detection methods. Sensors Mater. 2019:31:79-87.

4. Xue J, Chambers BS, Hensley SE, López CB. Propagation and characterization of influenza virus stocks that lack high levels of defective viral genomes and hemagglutinin mutations. Front Microbiol. 2016;7:1-15.

5. Grabowska I, Malecka K, Jarocka U, Radecki J, Radecka H. Electrochemical biosensors for detection of avian influenza virus - current status and future trends. Acta Biochim Pol. 2014;61:471-8.

6. Sueki A, Matsuda K, Yamaguchi A, Uehara M, Sugano M, Uehara T, et al. Evaluation of saliva as diagnostic materials for influenza virus infection by PCR-based assays. Clin Chim Acta. 2016;453:71-4. https://doi.org/10.1016/j. cca.2015.12.006

7. Dziabowska K, Czaczyk E, Nidzworski D. Detection methods of human and animal influenza virus—current trends. Biosensors. 2018;8:1-24.

8. Anusha JR, Kim BC, Yu KH, Raj CJ. Electrochemical biosensing of mosquitoborne viral disease, dengue: A review. Biosens Bioelectron. 2019;142:111511. https://doi.org/10.1016/j.bios.2019.111511.

9. Tan S, CMT D. MinION Direct RNA Sequencing and; 2019.

10. Thilakarathne DS, Hartley CA, Coppo MJC, Devlin JM, Date R, Date R, et al. Journal Pre-proof. 2019.

11. Zhao G, Shen W, Tuo D, Cui H, Yan P, Tang Q, et al. Rapid detection of two emerging viruses associated with necrotic symptoms in Areca catechu L. by reverse transcription loop-mediated isothermal amplification (RT-LAMP). J Virol Methods. 2019:2019:113795. https://doi.org/10.1016/j.jviromet.2019.113795.

12. Wang HB, Du T, Li WG, Zhao JH, Yang Z, Mo QH. The establishment and clinical evaluation of a novel, rapid, no-wash one-step immunoassay for the detection of dengue virus non-structural protein 1. J Virol Methods. 2020; 276(2019):113793. https://doi.org/10.1016/j.jviromet.2019.113793.

13. Tang YW, Lowery KS, Valsamakis A, Schaefer VC, Chappell JD, WhiteAbell J, et al. Clinical accuracy of a PLEX-ID flu device for simultaneous detection and identification of influenza viruses $a$ and B. J Clin Microbiol. 2013;51:40-5

14. Binnicker MJ, Espy MJ, Irish $\mathrm{CL}$, Vetter EA. Direct detection of influenza a and $B$ viruses in less than 20 minutes using a commercially available rapid PCR assay. J Clin Microbiol. 2015;53:2353-4.

15. Josephson KL, Gerba CP, Pepper IL. Polymerase chain reaction detection of nonviable bacterial pathogens. Appl Environ Microbiol. 1993:59:3513-5.

16. Nakaya Y, Stavrou S, Blouch K, Tattersall P, Ross SR. In vivo examination of mouse APOBEC3- and human APOBEC3A- and APOBEC3G-mediated restriction of parvovirus and Herpesvirus infection in mouse models. J Virol. 2016;90:8005-12.

17. Baer A, Kehn-Hall K. Viral concentration determination through plaque assays: Using traditional and novel overlay systems. J Vis Exp. 2014:1-10

18. Li D, De Keuckelaere A, Uyttendaele M. Application of long-range and binding reverse transcription-quantitative $P C R$ to indicate the viral integrities of noroviruses. Appl Environ Microbiol. 2014:80:6473-9.

19. Rodríguez RA, Bounty S, Linden KG. Long-range quantitative PCR for determining inactivation of adenovirus 2 by ultraviolet light. J Appl Microbiol. 2013;114:1854-65. 
20. Wolf S, Rivera-Aban M, Greening GE. Long-range reverse transcription as a useful tool to assess the genomic integrity of Norovirus. Food Environ Virol. 2009;1:129-36.

21. Allain J, Hsu J, Pranmeth M, Hanson D, Stassinopoulos A, Fischetti L, et al. Quantification of viral inactivation by photochemical treatment with Amotosalen and UV a light, using a novel polymerase chain reaction inhibition method with Preamplification. J Infect Dis. 2006;194:1737-44.

22. Simonet J, Gantzer C. Inactivation of poliovirus 1 and F-specific RNA phages and degradation of their genomes by UV irradiation at 254 nanometers. Appl Environ Microbiol. 2006;72:7671-7.

23. Chen JP, Yang L, Wang LK, Zhang B. Ultraviolet radiation for disinfection. In: Advanced Physicochemical Treatment Processes; 2006. p. 317-66.

24. Poepping C, Beck SE, Wright H, Linden KG. Evaluation of DNA damage reversal during medium-pressure UV disinfection. Water Res. 2014;56:181-9. https://doi.org/10.1016/j.watres.2014.02.043.

25. Eisfeld AJ, Neumann G, Kawaoka Y. At the Centre: influenza a virus ribonucleoproteins. Nat Rev Microbiol. 2015;13:28-41.

26. World Health Organization. Influenza ( Seasonal ) Ask the expert : Influenza Q \& A, vol. 2018: Who; 2018. p. 1-5. https://www.who.int/news-room/factsheets/detail/influenza-(seasonal.

27. Mcdonald SM, Nelson MI, Turner PE, Patton JT. Outcomes, vol. 14; 2016. p. 448-60.

28. World Health Organization. WHO information for molecular diagnosis of influenza virus in humans - update Laboratory tests Interpretation of PCR results. 2012. https://www.who.int/influenza/giss_laboratory/molecular_ diagnosis_influenza_virus_humans_update_201211.pdf.

29. Keller MW, Rambo-Martin BL, Wilson MM, Ridenour CA, Shepard SS, Stark TJ, et al. Direct RNA sequencing of the coding complete influenza a virus genome. Sci Rep. 2018;8:1-8.

30. Nishisaka-Nonaka R, Mawatari K, Yamamoto T, Kojima M, Shimohata T, Uebanso T, et al. Irradiation by ultraviolet light-emitting diodes inactivates influenza a viruses by inhibiting replication and transcription of viral RNA in host cells. J Photochem Photobiol B Biol. 2018;189:193-200. https://doi.org/ 10.1016/j.jphotobiol.2018.10.017.

31. Svoboda E. A sticking point for rapid flu tests? Nature. 2019;573:S56-7.

32. Simões J, Dong T. Continuous and real-time detection of drinking-water pathogens with a low-cost fluorescent optofluidic sensor. Sensors (Switzerland). 2018;18.

33. Koul PA, Mir H, Bhat MA, Khan UH, Khan MM, Chandha MS, et al. Performance of rapid influenza diagnostic tests (QuickVue) for influenza a and B infection in India. Indian J Med Microbiol. 2015;33:26-31.

34. Chander Y, Jindal N, Stallknecht DE, Sreevatsan S, Goyal SM. Full length sequencing of all nine subtypes of the neuraminidase gene of influenza a viruses using subtype specific primer sets. J Virol Methods. 2010;165:116-20. https://doi.org/10.1016/j.jviromet.2010.01.002.

35. Lawal O, Cosman J, Pagan J. UV-C LED devices and systems: current and future state. IUVA News. 2018;20:22-8 http://iuvanews.com/stories/pdf/ IUVA_2018_Quarter1_Lawal-article_hyperlinks.pdf.

36. Linden KG, Hull N, Speight V. Thinking outside the treatment plant: UV for water distribution system disinfection: Published as part of the Accounts of Chemical Research special issue "water for Two Worlds: Urban and Rural Communities.". Acc Chem Res. 2019;52:1226-33.

37. Thanapongtharm W, Van Boeckel TP, Biradar C, Xiao X, Gilbert M. Rivers and flooded areas identified by medium-resolution remote sensing improve risk prediction of the highly pathogenic avian influenza $\mathrm{H} 5 \mathrm{~N} 1$ in Thailand. Geospat Health. 2013;8:193-201.

38. Yan Y, Gu JY, Yuan ZC, Chen XY, Li ZK, Lei J, et al. Genetic characterization of H9N2 avian influenza virus in plateau pikas in the Qinghai Lake region of China. Arch Virol. 2017;162:1025-9.

39. Nakaya Y, Shojima T, Yasuda J, Miyazawa T. Unusual permeability of porcine endogenous retrovirus subgroup a through membrane filters. J Vet Med Sci. 2009. https://doi.org/10.1292/jvms.09-0184

40. Deng MY, Millien M, Jacques-Simon R, Flanagan JK, Bracht AJ, Carrillo C, et al. Diagnosis of porcine teschovirus encephalomyelitis in the Republic of Haiti. J Vet Diagn Investig. 2012;24:671-8.

41. Percival SL, Wyn-Jones P. Chapter Twenty-Two - Methods for the Detection of Waterborne Viruses BT - Microbiology of Waterborne Diseases (Second Edition); 2014. p. 443-70. https:/doi.org/10.1016/B978-0-12-415846-7.00022-6.

\section{Publisher's Note}

Springer Nature remains neutral with regard to jurisdictional claims in published maps and institutional affiliations.

Ready to submit your research? Choose BMC and benefit from:

- fast, convenient online submission

- thorough peer review by experienced researchers in your field

- rapid publication on acceptance

- support for research data, including large and complex data types

- gold Open Access which fosters wider collaboration and increased citations

- maximum visibility for your research: over $100 \mathrm{M}$ website views per year

At BMC, research is always in progress.

Learn more biomedcentral.com/submissions 